\title{
Clinical Validation of BCT Scores With Prognostic Factors in Hormone Receptor-positive, HER2-negative Early Breast Cancer
}

\author{
JEEYEON LEE ${ }^{1 *}$, WON HWA KIM ${ }^{2 \dagger}$, JIN HYANG JUNG ${ }^{1}$, WAN WOOK KIM ${ }^{1}$, \\ CHAN SUB PARK ${ }^{1}$, RYU KYUNG LEE ${ }^{1}$, JEE YOUNG PARK ${ }^{3}$, YEE SOO CHAE ${ }^{4}$, \\ SOO JUNG LEE ${ }^{4}$, HYE JUNG KIM ${ }^{2}$, JI-YOUNG PARK ${ }^{3 \dagger}$ and HO YONG PARK ${ }^{1 *}$ \\ ${ }^{1}$ Department of Surgery, School of Medicine, Kyungpook National University, Daegu, Republic of Korea; \\ ${ }^{2}$ Department of Radiology, School of Medicine, Kyungpook National University, Daegu, Republic of Korea; \\ ${ }^{3}$ Department of Pathology, School of Medicine, Kyungpook National University, Daegu, Republic of Korea; \\ ${ }^{4}$ Department of Hemato-Oncology, School of Medicine, Kyungpook National University, Daegu, Republic of Korea
}

\begin{abstract}
Background/Aim: Multigene profiling assays provide strong evidence for predicting the prognosis of breast cancer. In this study, we aimed to evaluate the clinical validation of the $B C T$ score with various prognostic factors. Materials and Methods: A total of 133 cases of hormone receptor-positive, cT1NO breast cancers were analyzed. Risk stratification using the BCT score (Low, $n=105$; High, $n=28$ ) was analyzed with Ki67 index, p53 mutation, Immunohistochemistry 4 (IHC4) score, Nottingham Prognostic Index (NPI) and online PREDICT. Results: Ki67 index and NPI showed strong correlations with risk stratification based on BCT scores. Although the IHC4 score and online PREDICT were not associated with BCT score, there was a significant tendency of association with the online PREDICT results as the time of overall survival was increasing. Conclusion: Risk classification based on BCT scores might have a clinical significance as a prognostic marker in hormone receptor-positive, HER2-negative, early breast cancer.
\end{abstract}

Personalized treatment of breast cancer is becoming increasingly popular, and guidelines are being developed on specific treatment plans based on patients' tumor and personal characteristics (1). Multigene tests, including

This article is freely accessible online.

*,†These Authors contributed equally to this study.

Correspondence to: Ho Yong Park and Ji-Young Park, Department of Surgery and Pathology, School of Medicine, Kyungpook National University, Hoguk-ro 807, Buk-gu, (41404) Daegu, Republic of Korea. Tel: +82 532002702, Fax: +82 532002072, e-mail: phy123@knu.ac.kr,jyppark@gmail.com

Key Words: Breast, carcinoma, BCT score, prognosis.
OncotypeDX ${ }^{\circledR}$, EndoPredict ${ }^{\circledR}$, and Mammaprint ${ }^{\circledR}$, can provide information to support the choice of treatment strategy (2). However, as most commercial multigene kits have been developed in western countries, their application in Asian female patients may be limited.

A 9-gene-based RNA test (GenesWell BCT ${ }^{\mathrm{TM}}$, Gencurix Inc., Seoul, South Korea), has been developed domestically for Korean patients and can predict 10-year distant metastasis risk in hormone receptor-positive, HER2negative, early breast cancer (3). In addition, the Breast Cancer Test (BCT) score, a prognostic predictor, can estimate tumor prognosis and chemotherapeutic benefits in clinically node-negative, luminal types of breast cancer (4, $5)$. Therefore, the BCT score may have both a prognostic and predictive value in early, luminal types of breast cancer.

The Ki67 index, p53 mutation, and results from immunohistochemical (IHC) examination of the estrogen receptor (ER), progesterone receptor (PR), and HER2 gene are prognostic or predictive factors for breast cancer, as has been reported previously (6-9). While the clinical significance and efficacy of p53 remain controversial, even though this molecule has long been studied as a predictive marker for breast cancer, the prognostic role of the Ki67 index has been proven in numerous studies $(10,11)$. However, the standard cutoff point for the Ki67 index (14\% versus $20 \%$ ) remains controversial (12-14).

Risk stratification based on multiple parameters, including IHC4 score, Nottingham Prognostic Index (NPI), online PREDICT, is the most important aspect of clinical practice for breast cancer treatment (15-18). In order to determine the best breast cancer treatment strategy, a physician should be able to discern between patients who do or do not need invasive treatment, such as chemotherapy. 
The BCT score had already been proven that provides information regarding patients who could benefit from chemotherapy (5). Based on this, we evaluated various clinicopathologic factors to identify whether BCT scores have any clinical correlations with recognized prognostic or predictive factors of breast cancer.

\section{Patients and Methods}

Among operable patients with breast cancers, those with hormone receptor-positive, HER2-negative breast cancers were retrospectively selected for this study. The inclusion criteria were as follows: 1) age more than 50 years, 2) single nodule of invasive ductal carcinoma ( $\leq 2$ $\mathrm{cm}$, cT1) 3) clinically node-negative (cN0) on preoperative mammography, ultrasonography, and breast MR. Patients with breast cancer who needed neoadjuvant treatment prior to surgery were excluded from this study. All experiments were performed in accordance with relevant guidelines and regulations. The requirement for informed consent was waived because the study was conducted retrospectively. All patient information was anonymized and deidentified prior to analysis.

Treatment strategy for breast cancer. The treatment strategy for each patient with breast cancer was decided following discussions by a multidisciplinary team that included breast and plastic surgeons, oncologists, radiologists, pathologists, radiation oncologists, and rehabilitation physicians.

During surgery, the breast tumors were removed with safe margins, and the surgical margins were evaluated pathologically for the presence of tumor cells through frozen biopsy. Negative resection margins were considered to have been achieved when there was no inked margin, and either sentinel node biopsy or axillary lymph node dissection was performed based on surgeon's opinion of the axillary lymph node status. After surgery, subsequent adjuvant radiotherapy, chemotherapy, or hormone treatment was performed when necessary.

Histopathological examination. The molecular subtype of the tumor was defined based on the immunohistochemical expression of the estrogen receptor (ER) and progesterone receptor (PR), and the HER2/neu gene amplification was examined using silver in situ hybridization (SISH). ASCO/CAP 2016 guidelines were used as the defining criteria for confirming the positive expression of ER/PR/HER2 in histological specimens.

Tissue preparation. A total of 160 formalin-fixed, paraffinembedded (FFPE) samples from archived surgical specimens were obtained for the 9-gene based multigene test, of which twenty-seven samples that were insufficient for appropriate analysis were excluded before the interpretation of the results. Clinical information, including patients' age, body mass index, clinical and pathologic tumor size, nodal status, pathologic stage, follow-up period, and oncologic outcomes, was obtained. Risk stratification results were obtained for 133 hormone receptor-positive, HER2negative breast cancer cases based on BCT scores (Figure 1).

Archived surgical specimens were treated as conventional FFPE tissue sections, and yielded three consecutive 10- $\mu \mathrm{m}$ curl-type sections. Tumor volume (\%), estimated by screening the representative slides, was calculated as the ratio between tumor and total parenchyma volume not including fat tissue. Each specimen was selected from a representative paraffin block after review by pathologists, and the samples were generally obtained from areas where at least $30 \%$ of the tissue volume included the tumor.

Stratification of risk group. The BCT score was calculated from the relative expression levels ( $\triangle \mathrm{Cp}$ values) of 6 prognostic genes (UBE2C, TOP2A, RRM2, FOXM1, MKI67, and BTN3A2), normalized using 3 reference genes (CTBP1, CUL1, and $U B Q L N 1)$, and clinical information on pathologic tumor size and nodal stage.

Based on a pre-defined cutoff score of 4.0, each case was categorized as either low- or high-risk (3), and cases with BCT scores higher than 4.0 classified into the high-risk group and those with scores lower than 4.0 classified into the low-risk group. Stratified risk groups were then evaluated for their clinical correlations with clinicopathologic characteristics and prognostic or predictive factors.

Ethical approval and consent to participate. This study was approved by the institutional review board (IRB) of Kyungpook National University Chilgok Hospital, Daegu, Republic of Korea (KNUCH 2018-06-014). All experiments were performed in accordance with relevant guidelines and regulations.

Statistical analysis. Statistical analysis for the evaluation of correlation between BCT score and other prognostic factors, including Ki67 index, NPI, IHC4 score and online PREDICT results, was performed with the chi-square test or Student's $t$-test depending on the presence of continuous or categorical variables using SPSS version 25 (SPSS Inc., Chicago, IL, USA). The Online PREDICT tool, version 2.1 was used via the PREDICT website (Eastern Cancer Registry and Information Centre and Cambridge University (2017). The oncologic outcomes were estimated using the Kaplan-Meier method, and statistical significance was defined as $p<0.05$.

\section{Results}

There were one-hundred and five low-risk and twenty-eight high-risk cases, as determined based on a cutoff BCT score of 4.0. There was no significant difference in age and body mass index between the two groups at the time of diagnosis. In both groups, the majority of cases involved breast conserving surgery $(85.7 \% \mathrm{vs} .75 .0 \%, p=0.401)$. Although there was no significant difference in clinical tumor size between the groups, axillary lymph node dissection was more commonly performed in the high-risk group (14.3\%, $p=0.034)$. Adjuvant chemotherapy and radiotherapy were more commonly administered in the high-risk group ( $p=0.001$ and 0.008 , respectively). However, the oncologic outcomes, including locoregional recurrence and distant metastasis, did not show any significant difference between the two groups. Moreover, all patients survived during the follow-up period (Table I, Figure 2).

The mean BCT scores were 2.67 and 4.55 in the low- and high-risk groups, respectively $(p=0.003)$. Mean pathologic tumor size and the incidence of axillary lymph node metastasis 


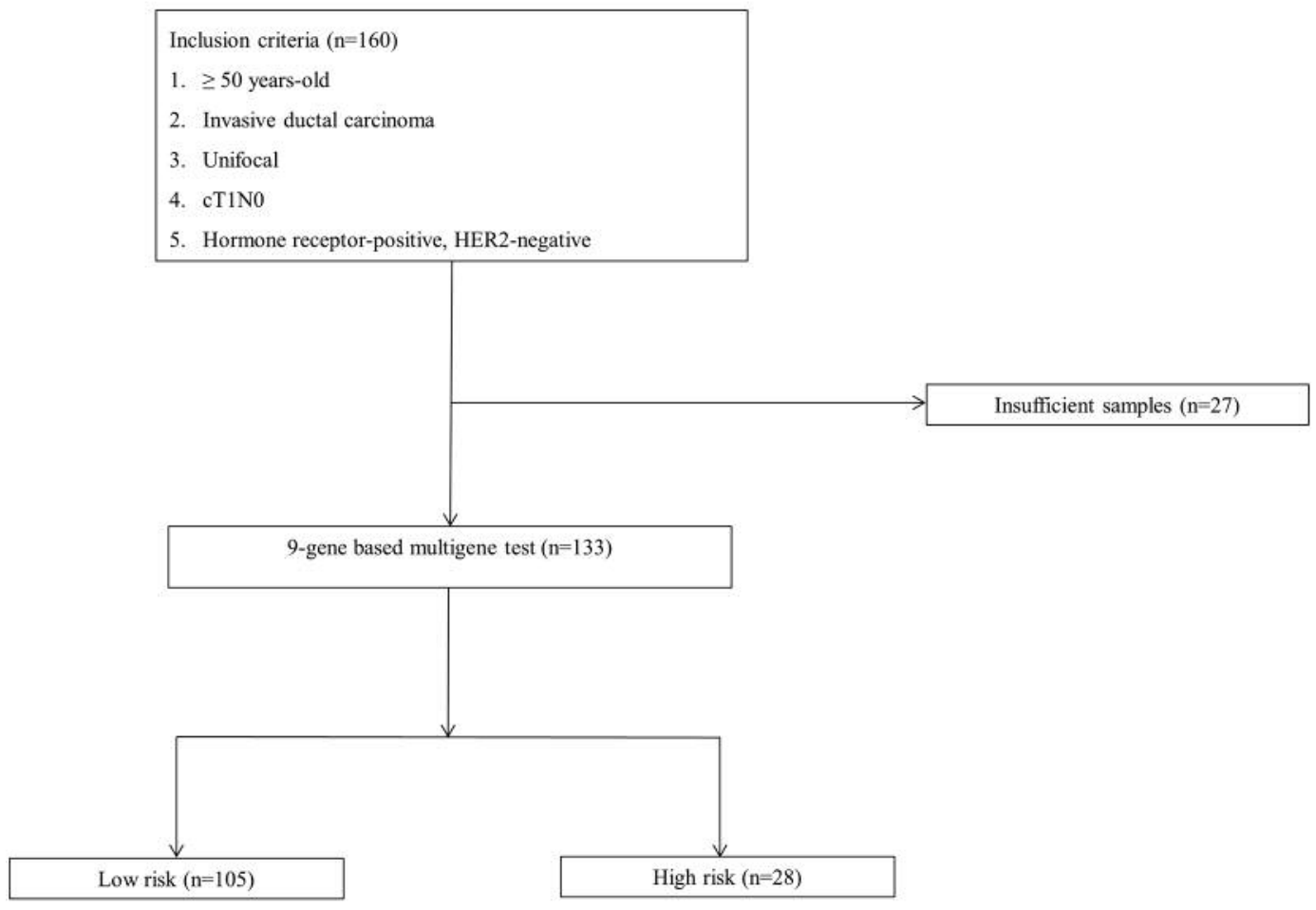

Figure 1. Specific inclusion criteria for hormone receptor-positive, HER2-negative, and clinically T1NO breast cancer. One-hundred and thirty-three cases were evaluated using the Breast Cancer Test (BCT) score, and twenty-eight high-risk cases were noted.

were larger and higher $(p=0.043$ and $<0.001)$, respectively, in the high-risk group. The distributions of histologic and p53 grades were similar in both groups (Table II).

The Ki67 index analysis was performed twice, once with a cutoff value of $14 \%$ and once with $20 \%$. While the analysis using the $14 \%$ cutoff value of $\mathrm{Ki} 67$ index, representing worse prognosis, showed a significant association with the BCT score in the high-risk group ( $p=0.004)$, using the $20 \%$ cutoff value yielded stronger statistical significance $(p<0.001)$. Regarding NPI, there was significant correlation in risk stratification between BCT score and NPI classification $(p=0.004)$. Although the IHC4 score and online PREDICT results were not matched in risk stratification with the BCT score, there was a significant tendency with online PREDICT results as the time of overall survival was increasing (Table III).

\section{Discussion}

Since breast cancer is very heterogeneous and individualized disease, risk stratification is of high significance. Not only immunohistochemical staining results for ER, PR, HER2, and Ki67 index, but gene expression data, can provide essential information on tumor prognosis. Based on these data, individualized treatment strategy for breast cancer could be established. However, the most important aspect is to distinguish between patients who require chemotherapy and those who do not.

Multigene profiling tests, which use molecular quantitative technology, have been developed to estimate the risk of local relapse or distant metastasis $(2,19-21)$. Several commercial multigene kits, such as OncotypeDX ${ }^{\circledR}$, Mammaprint ${ }^{\circledR}$, EndoPredict ${ }^{\circledR}$, are available. However, because these kits were developed with clinical data from western countries, they sometimes cannot be applied to Asian female patients $(22,23)$. A multigene test based on six prognostic genes - five of them involved in proliferation (UBE2C, TOP $2 A, R R M 2, F O X M 1$, and MKI67) and one involved in the immune system $(B T N 3 A 2)$ - as well as three reference genes (CTBP1, CUL1, and $U B Q L N 1$ ), has been developed using clinical data from Korean breast cancer patients $(3,4)$. The BCT score from this test has already been validated in independent cohorts of Korean patients with breast cancer, with results showing that it could predict chemotherapy benefits in hormone receptorpositive, HER2-negative breast cancer patients (5).

In this study, authors have investigated how closely the BCT score was correlated with prognostic factors already being used in the clinical field. Classic prognostic factors, including p53 and Ki67 index, were evaluated along with BCT scores, and the Ki67 index was found to show a strong correlation. 
Table I. Clinical characteristics of 133 patients with hormone receptor-positive, HER2-negative, cT1NO breast cancer who were examined using the 9-gene based multigene assay.

\begin{tabular}{|c|c|c|c|}
\hline & Low risk $(n=105)$ & High risk $(\mathrm{n}=28)$ & $p$-Value \\
\hline Mean age (years, \pm SD) & $60.51 \pm 7.83$ & $58.71 \pm 6.73$ & 0.270 \\
\hline Mean body mass index $\left(\mathrm{kg} / \mathrm{m}^{2}, \pm \mathrm{SD}\right)$ & $24.53 \pm 3.19$ & $24.01 \pm 3.24$ & 0.653 \\
\hline Type of breast surgery & & & 0.401 \\
\hline Breast conserving surgery & $90(85.7)$ & $21(75.0)$ & \\
\hline Partial mastectomy with reconstruction & $9(8.6)$ & $3(10.7)$ & \\
\hline Mastectomy with or without reconstruction & $6(5.7)$ & $4(14.3)$ & \\
\hline Type of axillary surgery & & & 0.034 \\
\hline Sentinel lymph node biopsy & $102(97.1)$ & $24(85.7)$ & \\
\hline Axillary lymph nodes dissection & $3(2.9)$ & $4(14.3)$ & \\
\hline Mean clinical tumor size $(\mathrm{cm}, \pm \mathrm{SD})$ & $1.49 \pm 0.68$ & $1.51 \pm 0.40$ & 0.269 \\
\hline Adjuvant chemotherapy $(\mathrm{n}, \%)$ & $20(19.0)$ & $11(39.3)$ & 0.001 \\
\hline Adjuvant radiotherapy $(\mathrm{n}, \%)$ & $96(91.4)$ & $23(82.1)$ & 0.008 \\
\hline Mean follow-up period (months, \pm SD) & $47.96 \pm 24.86$ & $46.39 \pm 24.72$ & 0.931 \\
\hline Locoregional recurrence $(\mathrm{n}, \%)$ & $2(1.9)$ & $1(3.6)$ & 0.340 \\
\hline Distant metastasis $(\mathrm{n}, \%)$ & $2(1.9)$ & $1(3.6)$ & 0.598 \\
\hline
\end{tabular}

Table II. Histopathological characteristics of 133 patients with hormone receptor-positive, HER2-negative, cT1NO breast cancer who were examined using the 9-gene based multigene test.

\begin{tabular}{|c|c|c|c|}
\hline & Low risk $(\mathrm{n}=105)$ & High risk $(n=28)$ & $p$-Value \\
\hline Mean BCT score $( \pm \mathrm{SD})$ & $2.67 \pm 0.89$ & $4.55 \pm 0.47$ & 0.003 \\
\hline Mean tumor volume in sample $(\%, \pm \mathrm{SD})$ & $49.57 \pm 18.79$ & $63.57 \pm 13.11$ & 0.843 \\
\hline Mean pathologic tumor size $(\mathrm{cm}, \pm \mathrm{SD})$ & $1.20 \pm 0.37$ & $1.50 \pm 0.26$ & 0.043 \\
\hline Axillary lymph node metastasis & $16(15.2)$ & $8(28.6)$ & $<0.001$ \\
\hline Histologic grade & & & 0.214 \\
\hline 1 & $26(24.8)$ & $2(7.1)$ & \\
\hline 2 & $69(65.7)$ & $21(75.0)$ & \\
\hline 3 & $10(9.5)$ & $5(17.9)$ & \\
\hline p53 gene mutation & & & 0.060 \\
\hline 0 & $72(68.6)$ & $19(67.9)$ & \\
\hline 1 & $20(19.0)$ & $6(21.4)$ & \\
\hline 2 & $9(8.6)$ & $1(3.6)$ & \\
\hline 3 & $4(3.8)$ & $2(7.1)$ & \\
\hline Ki67 index* & & & 0.004 \\
\hline
\end{tabular}

*Risk cutoff value of Ki67 index was determined as $14 \%$.

p53 gene mutation is a common prognostic factor in various human malignancies and is detected by immunohistochemical staining through the accumulation of nonfunctioning p53 protein in the nucleus (24). Although many researchers have reported that the overexpression of p53 protein indicates poor prognosis, overall survival, and disease free survival in breast cancer $(25-27)$, it is not specific for breast cancer; it is common in several human malignancies. In contrast, the Ki67 index has been considered a strong prognostic factor, especially in breast cancer, and is key in distinguishing Luminal A and B types of breast cancer $(10,12,28)$. However, the proliferation marker Ki67 index remains a controversial parameter, and its clinical utility has not been completely proven $(10,29)$. Moreover, its standard cutoff value has not yet been established (12-14).

The BCT score showed a strong correlation with the Ki67 index and there was also a tendency for consistency with the p53 status in our study. Based on clinical data from various independent breast cancer cohorts, the efficacy of the BCT score was validated. Therefore, we suggest that the BCT score can be used directly in clinical practice for selective cases, such as hormone receptor-positive, HER2-negative breast cancer cases of a clinical grade lower than T1 and N0.

However, the BCT score should be further assessed for its clinical value using several more breast cancer cases and a 
A Local control rate

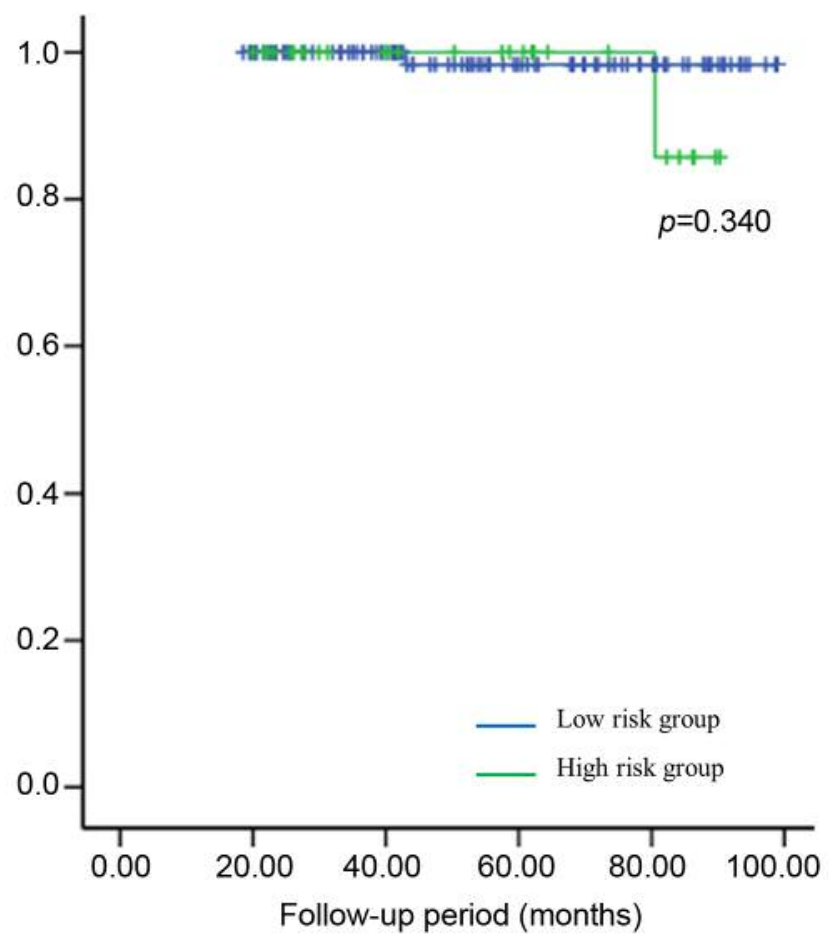

B Disease-free survival

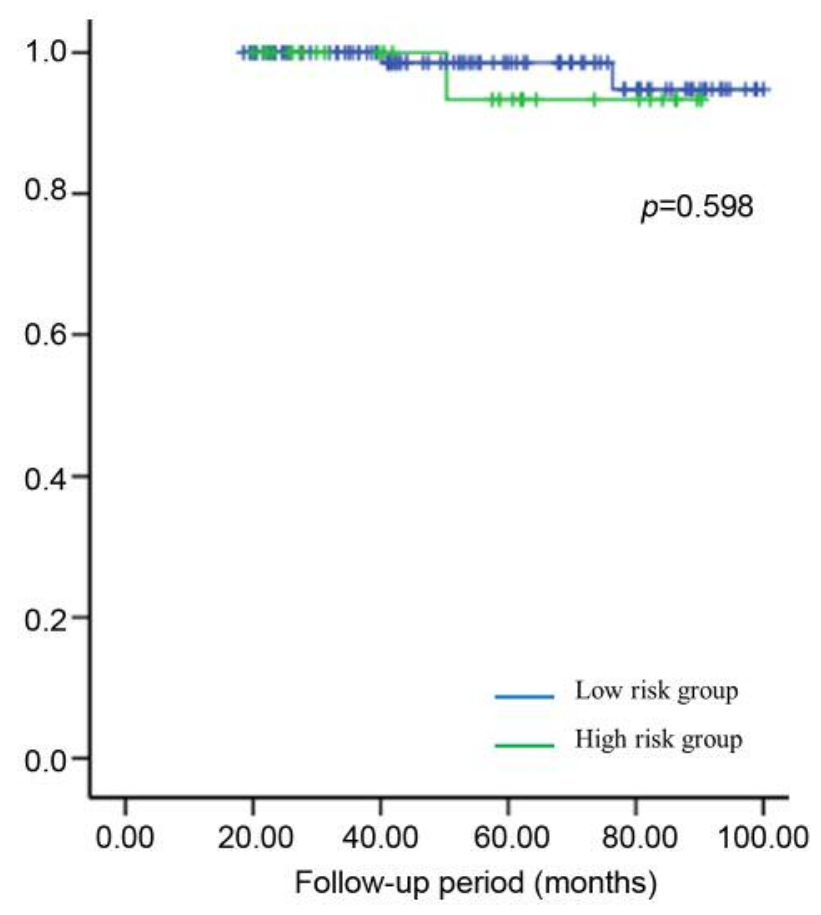

Figure 2. Oncologic outcomes of hormone receptor-positive, HER2-negative, and clinically T1NO breast cancer. (A) Because there was only one case of locoregional relapse in the low-risk group, a significant difference was not found between the low-and high-risk groups. (B) One case of distant metastasis, each, occurred in the low-and high-risk groups. Hence, significant differences were not found $(p=0.054)$.

longer follow-up period. In this study, because of the short follow-up period, oncologic events rarely occurred, and it was difficult to evaluate the correlation between oncologic outcomes and the BCT score.

In summary, the risk stratification based on BCT score was strongly correlated with the prognostic Ki67 index and NPI in Korean patients with hormone receptor-positive, HER2-negative, early breast cancer. Also, the online PREDICT showed a significant tendency of association with the BCT score. Therefore, BCT score could have clinical significance as a prognostic marker in such selective breast cancer cases.

\section{Conflicts of Interest}

The Authors declare no competing interests regarding this study.

\section{Availability of Data and Materials}

The Authors are not permitted to share data and materials. However, datasets are available from the corresponding Author on reasonable request.

\section{Authors' Contributions}

Guarantor of the integrity of the study: Jeeyeon Lee, Won Hwa Kim; Study concepts: Yee Soo Chae, Ho Yong Park; Study design: Jeeyeon Lee, Ho Yong Park; Definition of intellectual content: Jin Hyang Jung, Yee Soo Chae, Soo Jung Lee, Wan Wook Kim, Chan Sub Park, Ryu Kyung Lee; Literature research: Wan Wook Kim, Jeeyeon Lee, Chan Sub Park, Ryu Kyung Lee; Clinical studies: Jeeyeon Lee, Ho Yong Park, Ji-Young Park, Jee Young Park, Won Hwa; Kim, Hye Jung Kim; Data acquisition: Jeeyeon Lee, Soo Jung Lee; Data analysis: Jeeyeon Lee; Statistical analysis: Jeeyeon Lee; Manuscript preparation: Jeeyeon Lee, Jin Hyang Jung; Manuscript editing: Yee Soo Chae, Ho Yong Park; Manuscript review: Yee Soo Chae, Jin Hyang Jung.

\section{Acknowledgements}

The Authors would like to thank Gencurix Inc., (Seoul, Republic of Korea) for their support and advices. This work was supported by the National Research Foundation of Korea (NRF) grant funded by the Korea government (2014R1A5A2009242, 2017R1C1B5076186) and by a grant from the National R\&D Program for Cancer Control, Ministry of Health and Welfare, Republic of Korea (1420040). And this research was supported by a grant of the Korea Health 
Table III. Correlation between BCT scores and various prognostic factors in hormone receptor-positive, HER2-negative, cT1NO breast cancer.

\begin{tabular}{lccc}
\hline Prognostic factors & \multicolumn{2}{c}{ BCT score } & -Value \\
\cline { 2 - 3 } & $\begin{array}{c}\text { Low risk } \\
(\mathrm{n}=105)\end{array}$ & $\begin{array}{c}\text { High risk } \\
(\mathrm{n}=28)\end{array}$ & \\
\hline Ki67 index & & & \\
$<14 \%$ & $78(74.3)$ & $14(50.0)$ & 0.004 \\
$\geq 14 \%$ & $27(25.7)$ & $14(50.0)$ & \\
$<20 \%$ & $87(82.9)$ & $15(53.6)$ & $<0.001$ \\
$\geq 20 \%$ & $18(17.1)$ & $13(46.4)$ & \\
Nottingham Prognostic & & & \\
Index (NPI) & & & \\
Excellent & $23(21.9)$ & $2(7.1)$ & 0.004 \\
Good & $63(60.0)$ & $13(46.4)$ & \\
Moderate 1 & $17(16.2)$ & $13(46.4)$ & \\
Moderate 2 & $2(1.9)$ & - & \\
IHC4 score & & & \\
Low & $69(65.7)$ & $17(60.7)$ & 0.684 \\
Intermediate & $27(25.7)$ & $9(32.1)$ & \\
High & $8(7.62)$ & $2(7.1)$ & \\
PREDICT ver 2.1* & & & \\
5-year overall survival & 93.29 & 92.67 & 0.206 \\
10-year overall survival & 82.79 & 81.29 & 0.139 \\
15-year overall survival & 71.495 & 69.79 & 0.100 \\
\hline
\end{tabular}

*Online PREDICT tool, version 2.1 was used via the PREDICT website (Eastern Cancer Registry and Information Centre and Cambridge University (2017).

Technology R\&D Project through the Korea Health Industry Development Institute (KHIDI), funded by the Ministry of Health \& Welfare, Republic of Korea (HI17C1142). This work was supported by the National Research Foundation of Korea (NRF) grant funded by the Korea government (MSIT) (NRF-2019R1A2C1006264).

\section{References}

1 Cho SH, Jeon J and Kim SI: Personalized medicine in breast cancer: A systematic review. J Breast Cancer 15(3): 265-272, 2012. PMID: 23091538. DOI: 10.4048/jbc.2012.15.3.265

2 Chang MC, Souter LH, Kamel-Reid S, Rutherford M, Bedard P, Trudeau M, Hart J and Eisen A: Clinical utility of multigene profiling assays in early-stage breast cancer. Curr Oncol 24(5): e403-e422, 2017. PMID: 29089811. DOI: 10.3747/co.24.3595

3 Kim J KB, Bae S, Han S, Jun A, Han J, Cho M, Choi Y, Lee J and Moon Y: An analytical validation of the geneswelltm bct multigene prognostic test in patients with early breast cancer. Korean J Clin Lab Sci 49: 79-87, 2017.

4 Gong G, Kwon MJ, Han J, Lee HJ, Lee SK, Lee JE, Lee SH, Park S, Choi JS, Cho SY, Ahn SH, Lee JW, Cho SR, Moon Y, Nam BH, Nam SJ, Choi YL and Shin YK: A new molecular prognostic score for predicting the risk of distant metastasis in patients with hr+/her2- early breast cancer. Sci Rep 7: 45554, 2017. PMID: 28350001. DOI: 10.1038/srep45554
5 Kwon MJ, Lee SB, Han J, Lee JE, Lee JW, Gong G, Beitsch PD, Nam SJ, Ahn SH, Nam BH and Shin YK: Bct score predicts chemotherapy benefit in asian patients with hormone receptorpositive, her2-negative, lymph node-negative breast cancer. PLoS One 13(11): e0207155, 2018. PMID: 30462685. DOI: 10.1371/journal.pone. 0207155

6 Zaha DC: Significance of immunohistochemistry in breast cancer. World J Clin Oncol 5(3): 382-392, 2014. PMID: 25114853. DOI: $10.5306 /$ wjco.v5.i3.382

7 Perez-Lopez ME, Garcia-Gomez J, Alves MT, Paradela A, GarciaMata $\mathbf{J}$ and Garcia-Caballero T: Ki-67 is a prognostic marker for hormone receptor positive tumors. Clin Transl Oncol 18(10): 9961002, 2016. PMID: 26742937. DOI: 10.1007/s12094-015-1472-y

8 Jacquemier J, Moles JP, Penault-Llorca F, Adelaide J, Torrente M, Viens P, Birnbaum D and Theillet C: P53 immunohistochemical analysis in breast cancer with four monoclonal antibodies: Comparison of staining and pcr-sscp results. Br J Cancer 69(5): 846-852, 1994. PMID: 7514027. DOI: 10.1038/bjc.1994.164

9 Pan Y, Yuan Y, Liu G and Wei Y: P53 and ki-67 as prognostic markers in triple-negative breast cancer patients. PLoS One 12(2): e0172324, 2017. PMID: 28235003. DOI: 10.1371/journal. pone. 0172324

10 Jang MH, Kim HJ, Chung YR, Lee Y and Park SY: A comparison of ki-67 counting methods in luminal breast cancer: The average method vs. The hot spot method. PLoS One 12(2): e0172031, 2017. PMID: 28187177. DOI: 10.1371/journal.pone.0172031

11 de Azambuja E, Cardoso F, de Castro G Jr., Colozza M, Mano MS, Durbecq V, Sotiriou C, Larsimont D, Piccart-Gebhart MJ and Paesmans M: Ki-67 as prognostic marker in early breast cancer: A meta-analysis of published studies involving 12,155 patients. Br J Cancer 96(10): 1504-1513, 2007. PMID: 17453 008. DOI: $10.1038 /$ sj.bjc.6603756

12 Cheang MC, Chia SK, Voduc D, Gao D, Leung S, Snider J, Watson M, Davies S, Bernard PS, Parker JS, Perou CM, Ellis MJ and Nielsen TO: Ki67 index, her2 status, and prognosis of patients with luminal $\mathrm{b}$ breast cancer. J Natl Cancer Inst 101(10): 736-750, 2009. PMID: 19436038. DOI: 10.1093/ jnci/djp082

13 Goldhirsch A, Wood WC, Coates AS, Gelber RD, Thurlimann B and Senn HJ: Strategies for subtypes--dealing with the diversity of breast cancer: Highlights of the st. Gallen international expert consensus on the primary therapy of early breast cancer 2011. Ann Oncol 22(8): 1736-1747, 2011. PMID: 21709140. DOI: 10.1093/annonc/mdr304

14 Goldhirsch A, Winer EP, Coates AS, Gelber RD, Piccart-Gebhart M, Thurlimann B and Senn HJ: Personalizing the treatment of women with early breast cancer: Highlights of the st gallen international expert consensus on the primary therapy of early breast cancer 2013. Ann Oncol 24(9): 2206-2223, 2013. PMID: 23917950. DOI: 10.1093/annonc/mdt303

15 Natrajan $\mathrm{R}$ and Weigelt B: Risk stratification and intrinsic subtype classification of breast cancer: A multi-parameter test to rule them all? J Natl Cancer Inst 108(9), 2016. PMID: 27130931. DOI: 10.1093/jnci/djw118

16 Cuzick J, Dowsett M, Pineda S, Wale C, Salter J, Quinn E, Zabaglo L, Mallon E, Green AR, Ellis IO, Howell A, Buzdar AU and Forbes JF: Prognostic value of a combined estrogen receptor, progesterone receptor, ki-67, and human epidermal growth factor receptor 2 immunohistochemical score and comparison with the genomic health recurrence score in early 
breast cancer. J Clin Oncol 29(32): 4273-4278, 2011. PMID: 21990413. DOI: $10.1200 /$ jco.2010.31.2835

17 Green AR, Soria D, Powe DG, Nolan CC, Aleskandarany M, Szasz MA, Tokes AM, Ball GR, Garibaldi JM, Rakha EA, Kulka $\mathrm{J}$ and Ellis IO: Nottingham prognostic index plus (npi+) predicts risk of distant metastases in primary breast cancer. Breast Cancer Res Treat 157(1): 65-75, 2016. PMID: 27116185. DOI: 10.1007/ s10549-016-3804-1

18 de Glas NA, Bastiaannet E, Engels CC, de Craen AJ, Putter H, van de Velde CJ, Hurria A, Liefers GJ and Portielje JE: Validity of the online predict tool in older patients with breast cancer: A population-based study. Br J Cancer 114(4): 395-400, 2016. PMID: 26783995. DOI: 10.1038/bjc.2015.466

19 Filipits M, Rudas M, Jakesz R, Dubsky P, Fitzal F, Singer CF, Dietze O, Greil R, Jelen A, Sevelda P, Freibauer C, Muller V, Janicke F, Schmidt M, Kolbl H, Rody A, Kaufmann M, Schroth W, Brauch H, Schwab M, Fritz P, Weber KE, Feder IS, Hennig G, Kronenwett R, Gehrmann M and Gnant M: A new molecular predictor of distant recurrence in er-positive, her2-negative breast cancer adds independent information to conventional clinical risk factors. Clin Cancer Res 17(18): 6012-6020, 2011. PMID: 21807638. DOI: 10.1158/1078-0432.Ccr-11-0926

20 Rayhanabad JA, Difronzo LA, Haigh PI and Romero L: Changing paradigms in breast cancer management: Introducing molecular genetics into the treatment algorithm. Am Surg 74(10): 887-890, 2008. PMID: 18942607.

21 Sapino A, Roepman P, Linn SC, Snel MH, Delahaye LJ, van den Akker J, Glas AM, Simon IM, Barth N, de Snoo FA, van 't Veer LJ, Molinaro L, Berns EM, Wesseling J, Riley LB, Anderson D, Nguyen B and Cox CE: Mammaprint molecular diagnostics on formalin-fixed, paraffin-embedded tissue. J Mol Diagn 16(2): 190-197, 2014. PMID: 24378251. DOI: 10.1016/j.jmoldx. 2013.10.008

$22 \mathrm{Na}$ KY, Kim KS, Lee JE, Kim HJ, Yang JH, Ahn SH, Moon BI, Kim RM, Ko SM and Jung YS: The 70-gene prognostic signature for korean breast cancer patients. J Breast Cancer 14(1): 33-38, 2011. PMID: 21847392. DOI: 10.4048/ jbc.2011.14.1.33

23 Kim JM, Ryu JM, Kim I, Choi HJ, Nam SJ, Kim SW, Yu J, Lee SK and Lee JE: Verification of a western nomogram for predicting oncotype DX recurrence scores in korean patients with breast cancer. J Breast Cancer 21(2): 222-226, 2018. PMID: 29963119. DOI: $10.4048 /$ jbc.2018.21.2.222
24 Temmim L, Baker H and Sinowatz F: Immunohistochemical detection of p53 protein expression in breast cancer in young kuwaiti women. Anticancer Res 21(1b): 743-748, 2001. PMID: 11299837.

25 Ciesielski D, Dziewulska-Bokiniec A, Zoltowska A, Roszkiewicz A, Kopacz A and Wojtacki J: P53 expression in breast cancer related to prognostic factors. Neoplasma 42(5): 235-237, 1995. PMID: 8552201.

26 Pharoah PD, Day NE and Caldas C: Somatic mutations in the p53 gene and prognosis in breast cancer: A meta-analysis. Br J Cancer 80(12): 1968-1973, 1999. PMID: 10471047. DOI: 10.1038/sj.bjc.6690628

27 Yang P, Du CW, Kwan M, Liang SX and Zhang GJ: The impact of p53 in predicting clinical outcome of breast cancer patients with visceral metastasis. Sci Rep 3: 2246, 2013. PMID: 23873310. DOI: $10.1038 /$ srep02246

28 Criscitiello C, Disalvatore D, De Laurentiis M, Gelao L, Fumagalli L, Locatelli M, Bagnardi V, Rotmensz N, Esposito A, Minchella I, De Placido S, Santangelo M, Viale G, Goldhirsch A and Curigliano G: High ki-67 score is indicative of a greater benefit from adjuvant chemotherapy when added to endocrine therapy in luminal $\mathrm{b}$ her2 negative and node-positive breast cancer. Breast 23(1): 69-75, 2014. PMID: 24314620. DOI: 10.1016/j.breast.2013.11.007

29 Focke CM, Burger H, van Diest PJ, Finsterbusch K, Glaser D, Korsching E and Decker T: Interlaboratory variability of ki67 staining in breast cancer. Eur J Cancer 84: 219-227, 2017. PMID: 28829990. DOI: 10.1016/j.ejca.2017.07.041
Received August 1, 2019

Revised August 15, 2019

Accepted August 16, 2019 